\title{
The Effect of Theory Based Nutritional Education on Fat Intake, Weight and Blood Lipids
}

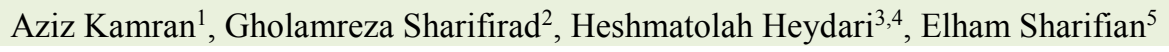

${ }^{1}$ Ph.D. of Health Education and Promotion, Assistant Professor, Public Health Department, Khalkhal Faculty of Medical Sciences, Ardabil University of Medical Sciences, Ardabil, Iran

${ }^{2} \mathrm{Ph} . \mathrm{D}$. of Health Education and Promotion, Professor, Islamic Azad University, Qom Branch, Qom, Iran

${ }^{3}$ Ph.D. of Community Health Nursing, Assistant Professor, Department of Community Health Nursing, School of Nursing and Midwifery, Lorestan University of Medical Sciences, Khorramabad, Iran

${ }^{4} \mathrm{Ph}$.D. of Community Health Nursing, Assistant Professor, Department of Community Health Nursing, School of Nursing and Midwifery, Tehran University of Medical Sciences, Tehran, Iran

${ }^{5}$ M.Sc., Nursing Department, Nursing School, Khalkhal Faculty of Medical Sciences, Ardabil University of Medical Sciences, Ardabil, Iran

\section{Type of article: Original}

\begin{abstract}
Introduction: Though Nutrition plays a key role in the control of hypertension, it is often forgotten in Iranian patients' diet. In fact, dietary behavior can be regarded as unsatisfactory among Iranian patients. This study was aimed to assess the effectiveness of theory based educational intervention on fat intake, weight, and blood lipids among rural hypertensive patients.

Methods: This quasi experimental study was conducted on 138 hypertensive patients who had referred to Ardabil rural health centers during 2014. The nutritional education based on DASH and Health Promotion Model (HPM) was treated for six sessions. The pre-test and post-test had intervals of two and six months. Data were analyzed using SPSS-18 and Chi-square, independent-samples t-test, paired-samples t-test and repeated measure ANOVA.

Results: After treating intervention, weight, dietary fat, LDL_C and Total cholesterol, systolic and diastolic blood pressures decreased significantly in the intervention group compared with the control group $(\mathrm{p}<0.001)$. In contrast, HDL_C increased significantly in the intervention group.

Conclusion: Educational intervention, provided based on Pender's health promotion model, affecting fat intake, blood lipids, and blood pressure, led to their decrease

Keywords: Blood lipids, Blood Pressure, Education, Fat intake, Weight
\end{abstract}

\section{Introduction}

Lifestyle changes can affect blood pressure; in this regard, beneficial effects of nutrition on health and blood pressure control have been reported (1) in the literature. Accordingly, nutrition is regarded as one of the most important aspects of life style for controlling blood pressure $(2,3)$. Also, nutrition is considered as a first step and starting line for controlling blood pressure (BP in stage 1 hypertension (4). Therefore, adherence to dietary recommendations such as Dietary Approach to Stop Hypertension (5) can be effective in reducing BP (6). However, few studies have demonstrated the widespread adherence to the DASH diet in both hypertensive and healthy people (7). According to findings, nutritional status in dietary behavior is inappropriate in Iran and the prevalence of hypertriglyceridemia and hypercholesterolemia has been reported as $36.4 \%$ and $42.9 \%$, respectively (8). Over a thirty year period, dietary fat can increase considerably, and usually consists of saturated fat, salt, and sugar, as consumption of fruit, vegetables and fish is inadequate in the Iranian diet. In a study which was conducted among the rural and urban population in Ardabil Province in Iran,, over 80\% of rural people used solid vegetable oil for

\section{Corresponding author:}

Assistant Professor Dr. Heshmatolah Heydari, Department of community Health Nursing, School of Nursing and Midwifery, Lorestan University of Medical Sciences, Khorramabad, Iran.

Tel: +98.9166632337, Email: hidari74@gmail.com

Received: April 16, 2016, Accepted: November 10, 2016, Published: December 2016

iThenticate screening: September 14, 2016, English editing: November 27, 2016, Quality control: December 05, 2016 (C) 2016 The Authors. This is an open access article under the terms of the Creative Commons Attribution-NonCommercialNoDerivs License, which permits use and distribution in any medium, provided the original work is properly cited, the use is non-commercial and no modifications or adaptations are made. 
cooking and more than $13 \%$ used butter and animal oil which was significantly higher than the percentage reported for the urban population (10). Several factors play important roles in determining nutritional behavior. Among these, leading factors are taste, cost, and convenience. However, these three factors, cannot determined nutritional behavior alone. According to a study by Glanz (1998), several factors influence dietary behavior among which are being more conscious of the psychological and environmental factors that could be a barrier against healthy eating, and controlling and preventing hypertension which can maximize the effectiveness of nutrition interventions (11). Dietary patterns are influenced by many factors such as interpersonal, intrapersonal, cultural, and environmental factors that can promote or hinder healthy eating. likewise, adherence to the DASH diet can, also be influenced by these factors (12). In addition to demographic factors such as age, gender, education level, and other modifiable factors, identification and consideration of which, is as a first step in strengthening dietary adherence in the educational interventions, there are, also, other factors more influential in this regard. These factors include knowledge $(13,14)$, benefits of healthy eating $(15,16)$, barriers $(15,17-19)$, self efficacy $(20,21)$, subjective norms $(22,23)$, environmental factors $(24)$, factors affecting healthy eating $(18,25)$, and temptations $(26,27)$. Therefore, considering the importance of nutritional behavior in hypertension control that is influenced by several factors, health care providers should use psychological approaches to increase efficiency in dietary intervention; furthermore, there is a necessity to understand opinions on other aspects such as personal belief and social context of behavior. Attention to these factors is essential in designing effective strategies (19). Therefore, a theoretical framework paved the way for program planning in the present study. With regard to the mentioned factors affecting dietary adherence in hypertensive patients, reported in numerous studies, it seemed that Health Promotion Model (HPM) is suitable as a framework for the present study. The pilot study proved the effects of perceived benefits and barriers, self-efficacy, proper predictive power of nutrition behavior, and dietary adherence in patients with hypertension (24). Therefore, HPM was selected as a theoretical framework for the present study.

\section{Material and Methods}

\subsection{Research design and sampling}

This research enjoyed a quasi-experimental pre-test/post-test design which was supported, funded, and approved by Institutional Review Board of Isfahan University of Medical Sciences No: 392132. The study population included hypertensive patients in rural health centers in Ardabil in 2014 which were selected with a multi-stage random sampling method. Thus, 140 people were assigned to experimental and control groups ( 70 as experimental patients, and 70 as control patients) based on repeated measure sampling formula ( $\mathrm{v}=1, \mathrm{w}=2, \rho=0.6, \alpha=0.05)$. During the study, two patients were excluded from the experimental group because of immigration.

\subsection{Allocation of participants into groups}

To select samples of case and control groups, the researchers randomly selected 4 rural health centers in first stage. Then, patients of 2 centers were randomly assigned as the treatment group, and patients of the other 2 centers participated as control group. In the third stage, the samples, in each center, were randomly selected from among patients with systolic blood pressure $\geq 140 \mathrm{mmHg}$ or diastolic blood pressure $\geq 90 \mathrm{mmHg}$. Other included criteria were age range of 30-65, tendency for conscious participation, and the ability to read and write. Excluded criteria, also, included suffering from complications of hypertension, need for another special diet for any reason, and other medical conditions.

\subsection{Study variable}

The outcome variables include diastolic and systolic blood pressures, HDL, LDL, total cholesterol, dietary total and saturated fat, weight and dietary cholesterol. Age, gender and medication usage can play confounding variable role in this study but results showed that there was no significant difference in these variables between two groups.

\subsection{Instrument}

A questionnaire with 3 sections was used for data collection: 1. Demographic questions, 2. Dietary intake assessed by 3-day food record, and 3. Laboratory data checklist. The data were collected using interviews before treatment and in follow up periods of 2 and 6 months after the intervention, by trained personnel who were trusted by the patients. A questionnaire with 3 sections was used for data collection: 1. Demographic questions, 2. Dietary intake assessed by 3-day food record, and 3. Laboratory data checklist.

\subsection{Experiment and data collection}

The designed treatment included nutritional advice about the DASH approach which was presented in 6 group teaching sessions (i.e. 2 sessions per week). For the convenience of the patients and to increase their participation, the researchers decided to hold the sessions in selected rural health centers. Moreover, to increase the motivation of 
the patients, the researchers utilized Pender's Health Promotion Model structures. In the first session, the benefits and barriers of the diet, as well as interpersonal factors were explained in the presence of one of the patient's family members as social support resource in a group discussion held for 90 minutes to 2 hours. The raised questions were answered at the end of the session. In the second session, patients' viewpoints about nutritional behavior were discussed with the patients explaining their negative and positive viewpoints about dietary adherence. Then, their negative viewpoints were evaluated and compared with benefits of healthy dietary behavior perceived by them. In this regard, in the 2-5 sessions, some guidelines recommended by the DASH approach (food, units, sizes, resources and skills in selecting food, and preparing and dividing daily meal units) were taught within 60 to 75 minutes. Furthermore, to enhance self-efficacy and the skills of the patients, the researchers asked them to provide their daily nutrition program and adhere to the provided recommendations to regulate their diet in the last four sessions. In the sixth session, patients' completed daily dietary plans were evaluated and feedback was given to improve them. At the beginning and the end of the last session, behavioral commitment of the patients to adhere to dietary recommendations was emphasized. All patients verbally committed to adhere to dietary instructions. In this regard for strengthening their commitment, educational pamphlets and booklets were distributed among the patients, monthly. The entire educational program was provided by AK (Ph.D. in Health Promotion). For ethical considerations, after completing the study, the instruction booklets were also distributed among the control group.

\subsection{Statistical analysis}

Data were analyzed using SPSS version 18 (SPSS Inc., Chicago, IL, USA). Independent-samples t-test was employed to compare the values between the two groups before and after the intervention. The mean differences of variables were compared by paired-samples t-test. Furthermore, repeated measures analysis of variance was used to test the group in terms of time effects. $P$ values less than 0.05 were considered significant.

\subsection{Ethics of research}

The goals and confidentiality of the information were explained and informed consent was obtained from the participants who agreed to participate in the study. Also, The researcher obtained the necessary licenses from the Research Council and the Ethics Committee of Isfahan University of Medical Sciences and Ardabil Health Care Services confirmed the study and an introduction letter from Ardabil University of Medical Sciences was sent to the head of the rural health centers.

\section{Results}

The mean age of patients who participated in the experimental group was 49.6 and was 50.9 in the control group. There was no significant difference in the mean age, mean duration of disease, education level, or gender of the patients in both groups (Table 1). No significant difference was observed between the two groups in total and saturated fat intake before intervention, however, 2 and 6 months after the intervention, a significant difference was found in the mean changes of fat intake among the two groups. Repeated measure tests showed that intervention had a significant effect on total and saturated fat intake in the experimental group over time $(\mathrm{p}<0.001)$; it had significantly decreased.

Table 1. Demographic characteristics of hypertensive patients in the case and control groups

\begin{tabular}{|c|c|c|c|c|}
\hline \multirow{2}{*}{\multicolumn{2}{|c|}{ Variable }} & \multicolumn{2}{|l|}{ Group } & \multirow[t]{2}{*}{ p-value } \\
\hline & & Experiment $(\mathrm{n}=68)$ & Control $(n=70)$ & \\
\hline \multirow[t]{2}{*}{ Sex } & Male & $19(27.9 \%)$ & $15(21.4 \%)$ & \multirow[t]{2}{*}{0.3} \\
\hline & Female & $49(72.1 \%)$ & $55(78.6 \%)$ & \\
\hline \multirow[t]{3}{*}{ Education } & Primary School & $49(72.1 \%)$ & $57(81.4 \%)$ & \multirow[t]{3}{*}{0.1} \\
\hline & Mid School & $18(26.5 \%)$ & $10(14.3 \%)$ & \\
\hline & High School & $1(1.5 \%)$ & $3(4.3 \%)$ & \\
\hline \multirow[t]{3}{*}{ Medication use } & Regularly (on time) & $42(61.58 \%)$ & $38(54.3 \%)$ & \multirow[b]{3}{*}{0.4} \\
\hline & Irregularly & $26(38.2 \%)$ & $31(44.3 \%)$ & \\
\hline & No consumption & 0 & $1(1.4 \%)$ & \\
\hline \multicolumn{2}{|c|}{ Age (year); Mean \pm SD } & $49.6 \pm 6.7$ & $50.9 \pm 6.1$ & 0.23 \\
\hline \multicolumn{2}{|c|}{ Systolic BP (mmhg) ; Mean \pm SD } & $145.1 \pm 9$ & $146.2 \pm 9.6$ & 0.47 \\
\hline \multicolumn{2}{|c|}{ Disease duration (year) ; Mean \pm SD } & $5.6 \pm 3.9$ & $5.9 \pm 3.6$ & 0.6 \\
\hline
\end{tabular}


http://www.ephysician.ir

Also, no significant difference was seen between the two groups in dietary cholesterol intake before intervention, although 2 and 6 months after the intervention, a significant difference was found in the mean changes of fat intake among the two groups. Repeated measure tests showed that intervention had a significant effect on cholesterol intake in the case group over time $(\mathrm{p}<0.001)$; it had significantly decreased. There was no significant difference between the mean of weight between the two groups' before the intervention. However, 2 and 6 months after the intervention, a significant change was found in the mean of weight among the experimental group. Repeated measuring tests showed that intervention had a significant effect on weight in the experimental group over time $(\mathrm{p}<0.001)$; it had significantly decreased (Table 2$)$.

Table 2. Mean of dietary total and saturated fat, Cholesterol and Weight in case and control group before and after intervention

\begin{tabular}{|c|c|c|c|c|c|c|}
\hline \multirow{2}{*}{\multicolumn{2}{|c|}{ Variables }} & \multicolumn{2}{|c|}{ Experiment group } & \multicolumn{2}{|c|}{ Control group } & \multirow[t]{2}{*}{ p-value } \\
\hline & & Mean & SD & Mean & SD & \\
\hline \multirow[t]{4}{*}{ Total Fat intake (gr/day) } & Baseline & 90.7 & 34.8 & 83 & 21.8 & \multirow[t]{3}{*}{$<0.001$} \\
\hline & Changes after 2 month & -43.8 & 33.9 & -7.3 & 24.6 & \\
\hline & Changes after 6 month & -51.6 & 36.5 & -0.7 & 27.1 & \\
\hline & Repeated Measure & \multicolumn{2}{|c|}{$\mathrm{p}<0.001$} & \multicolumn{2}{|c|}{$p=0.02$} & \\
\hline \multirow[t]{4}{*}{ Saturated fat (gr/day) } & Baseline & 33.5 & 10.1 & 29.9 & 8.3 & \multirow[t]{3}{*}{$<0.001$} \\
\hline & Changes after 2 month & -17.4 & 10.2 & -2.3 & 9.9 & \\
\hline & Changes after 6 month & -13.8 & 10.6 & 4.2 & 10.3 & \\
\hline & Repeated Measure & \multicolumn{2}{|c|}{$\mathrm{p}<0.001$} & \multicolumn{2}{|c|}{$\mathrm{p}<0.001$} & \\
\hline \multirow[t]{4}{*}{ Dietary Cholesterol (mg/day) } & Baseline & 460.8 & 237.2 & 398.1 & 180.1 & \multirow[t]{3}{*}{$<0.001$} \\
\hline & Changes after 2 month & -132.3 & 291.2 & 26.4 & 259.9 & \\
\hline & Changes after 6 month & -204.7 & 297.5 & 124.6 & 276.8 & \\
\hline & Repeated Measure & \multicolumn{2}{|c|}{$\mathrm{p}<0.001$} & \multicolumn{2}{|c|}{$\mathrm{p}=0.001$} & \\
\hline \multirow[t]{4}{*}{ Weight (kg) } & Baseline & 77.3 & 11.2 & 76.1 & 12.4 & \multirow[t]{4}{*}{$<0.001$} \\
\hline & Changes after 2 month & -3.7 & 1.4 & 0.001 & 2 & \\
\hline & Changes after 6 month & -8.6 & 3 & -0.6 & 2.7 & \\
\hline & Repeated Measure & \multicolumn{2}{|c|}{$\mathrm{p}<0.001$} & \multicolumn{2}{|c|}{$\mathrm{p}=0.057$} & \\
\hline
\end{tabular}

Table 3. Mean of blood lipids and blood pressure in case and control group before and after intervention

\begin{tabular}{|c|c|c|c|c|c|c|}
\hline \multirow{2}{*}{\multicolumn{2}{|c|}{ Variables }} & \multicolumn{2}{|c|}{ Experiment group } & \multicolumn{2}{|c|}{ Control group } & \multirow[t]{2}{*}{ p-value } \\
\hline & & Mean & SD & Mean & SD & \\
\hline \multirow[t]{4}{*}{ HDL-C (mg/dl) } & Baseline & 47.4 & 7.4 & 46.9 & 5.4 & \multirow[t]{3}{*}{$<0.001$} \\
\hline & Changes after 2 month & 4.7 & 8.6 & -2.0 & 5.9 & \\
\hline & Changes after 6 month & 12.2 & 12.7 & 2 & 10.7 & \\
\hline & Repeated Measure & \multicolumn{2}{|c|}{$\mathrm{p}<0.001$} & \multicolumn{2}{|c|}{$\mathrm{p}=0.003$} & \\
\hline \multirow[t]{4}{*}{ Total Cholesterol (mg/dl) } & Baseline & 218.5 & 39.4 & 202.6 & 40.9 & \\
\hline & Changes after 2 month & -18.5 & 11.4 & -4.6 & 12.3 & \\
\hline & Changes after 6 month & -26.0 & 17.7 & 17.2 & 20 & \\
\hline & Repeated Measure & \multicolumn{2}{|c|}{$\mathrm{p}<0.001$} & \multicolumn{2}{|c|}{$\mathrm{p}<0.001$} & \\
\hline \multirow[t]{4}{*}{ LDL-C (mg/dl) } & Baseline & 127.8 & 34.3 & 110.5 & 31.9 & \multirow[t]{3}{*}{$<0.001$} \\
\hline & Changes after 2 month & -17 & 11.3 & -1.9 & 7.7 & \\
\hline & Changes after 6 month & -30.3 & 17.2 & 11 & 13.8 & \\
\hline & Repeated Measure & \multicolumn{2}{|c|}{$\mathrm{p}<0.001$} & \multicolumn{2}{|c|}{$\mathrm{p}<0.001$} & \\
\hline \multirow[t]{4}{*}{ Systolic BP (mmHg) } & Baseline & 145.1 & 9.2 & 146.2 & 8.8 & \multirow[t]{3}{*}{$<0.001$} \\
\hline & Changes after 2 month & -11.3 & 7.8 & 0.1 & 7.8 & \\
\hline & Changes after 6 month & -13.0 & 10.2 & 0.5 & 12.2 & \\
\hline & Repeated Measure & \multicolumn{2}{|c|}{$\mathrm{p}<0.001$} & \multicolumn{2}{|l|}{$\mathrm{p}=0.8$} & \\
\hline \multirow[t]{4}{*}{ Diastolic BP (mmHg) } & Baseline & 89.2 & 3.5 & 90 & 6.1 & \multirow[t]{4}{*}{$<0.001$} \\
\hline & Changes after 2 month & -5.7 & 4.9 & -0.8 & 5.8 & \\
\hline & Changes after 6 month & -7.3 & 5.3 & -0.7 & 7.8 & \\
\hline & Repeated Measure & \multicolumn{2}{|c|}{$\mathrm{p}<0.001$} & \multicolumn{2}{|l|}{$p=0.5$} & \\
\hline
\end{tabular}


Results showed that six months after the intervention, total and LDL cholesterol reduced $30.3 \mathrm{mg} / \mathrm{dl}$ and $26 \mathrm{mg} / \mathrm{dl}$, respectively; and a significant increase was observed in the concentrations of HDL cholesterol in 2 and 6 month after intervention (Table 3). Before the educational program, the mean of systolic blood pressure of the experimental and control group was $145.1 \pm 9.2 \mathrm{~mm} \mathrm{Hg}$ and $146.2 \pm 8.8 \mathrm{~mm} \mathrm{Hg}$, respectively. Diastolic blood pressure in the experimental and control group was $89.2 \pm 3.5 \mathrm{~mm} \mathrm{Hg}$ and $90.0 \pm 6.1 \mathrm{~mm} \mathrm{Hg}$, respectively. Moreover, no significant difference was seen in the systolic and diastolic blood pressures between the two groups. However, 2 and 6 months after the intervention, systolic blood pressure in the experimental group statistically decreased (11.3 and $13 \mathrm{~mm} \mathrm{Hg}$, respectively). Repeated measure ANOVA tests, also, showed that the educational program had a significant effect on the systolic and diastolic blood pressures in the treatment group over time $(p<0.001)$ with a significant decrease, but these changes were not significant in the control group over time (Table 3).

\section{Discussion}

Fats are necessary, to provide essential fatty acids and to absorb fat-soluble vitamins. These nutrients have highcalorie and favorable taste (28). The mean of fat intake in both groups was higher than which was advised to these patients, and was similar to Iranian dietary pattern (30\% derived from fat) (29). This is in line with the study of Guo (2002) which reported more than $30 \%$ calories provided by fat among hypertension patients (30). The results of the present study showed that the educational intervention based on DASH had a significant effect on the systolic and diastolic blood pressures in the treatment group over time. However, the educational interventions provided by the DASH approach were not always successful in lowering blood pressure. The PREMIER study, conducted following the period of six months, found no distinct advantage for DASH approach compared with other lifestyle interventions (31). In another study, Whitt-Glover found no significant decrease in blood pressure after nine training sessions and twelve follow-up weeks (32). Similarly, Rankins (2005) assessing the effectiveness of nutritional education with DASH approach based on social cognitive model structures, even with opportunities for education and social support along with free dinner, found no desired results after 30 days of intervention (33). In the original DASH study, all meals were provided for 459 participants who had untreated systolic and diastolic blood pressure ; the study showed a slight decrease in mean of systolic and diastolic blood pressure after eight weeks (34). Another feeding study showed similar decrease in systolic and diastolic blood pressure (35). The PREMIER study was an RCT to test whether counseling on making several lifestyle changes at once, could reduce or control high blood pressure (36). The PREMIER was not a feeding study; thus, participants did not adhere to the dietary guidelines. However in our study, participants were taught how to design a DASH eating plan; thus, they reported decrease in their fat consumption and increase in their confidence in consuming healthier food. Therefore, the results of this study showed a decrease in blood pressure similar to those observed in the DASH feeding studies. This highlights the potential for translatability and sustainability of our educational program. After the intervention, fat intake significantly reduced in the experimental group but increased in the control group. Evidence from an experimental review study conducted on 104 studies showed that about three-quarters of interventions have been successful in total fat and saturated fat reduction (37). Fat intake reduction in the present study is consistent with the results reported by other studies (38-41). Also, in Epstein's study (2012), total and saturated fat significantly reduced after nutritional intervention was based on DASH (42). Reducing fat intake is very important in hypertensive patients, since high fat diet can increase BP (43). Quality and quantity of fat in the diet is also important, since they affect the risk of cardiovascular disease (CVD). Moreover, it was revealed that changing dietary saturated fat to monounsaturated fat (MUFA) lead to a significant decrease in blood pressure (44). The effect of dietary fat reduction on weight loss has been demonstrated in several studies $(37,45)$. Moreover, reduction of saturated fatty acids is advised for reducing cardiovascular risk (46). In this regard, America Heart Association recommends that less than $7 \%$ of calories should come from saturated fat (47); since, saturated fat can increase total cholesterol and LDL levels compared with carbohydrate. Positive association between saturated fat intake and blood pressure has, also, been reported (46). In this study, a significant increase was observed in the amount of fat intake in the control group over time, which can be justified by the changes made in dietary patterns in specific seasons. This finding is in line with the results of $\mathrm{Ma}$ (2006) who found that fat intake was higher during fall (end of the present study) than in spring (at the baseline of the present study) (48). Increased fat intake in the control group which may, possibly, be the result of seasonal variations in dietary pattern, was not observed in the intervention group. This can be due to the influence of treatment; and, not being affected by seasonal variations in dietary pattern can be considered a remarkable point of this study. After intervention, the mean of HDL-C in the experimental group significantly increased. However, changes in control group was, also, significant. This is consistent with the findings of other research $(29,49-51)$ that reported that HDL-C increase in intervention group with DASH compared with the control diet. In Li's study, low fat diet increased HDL-C in participants (52). With regard to the normal range of cholesterol and plasma lipid indices (31), we can say that patients had high blood cholesterol, which is consistent with a similar 
study conducted on patients with hypertension and serum cholesterol levels compared with those with normotensive people (38). This is in line with Iranian studies showing that Hypercholesterolemia have been introduced as a health problem in northern Iran (53). Results showed that LDL-C and Total cholesterol significantly decreased in the interventional group, but significantly increased in control group over time. This finding is in line with other studies $(41,51,54,55)$ in that LDL-C and Total cholesterol significantly decreased. However, in the study by Nowson no changes were found in serum lipids except for a significant increase in HDL-C (56). In the present study, the researchers found statistically significant changes in mean serum lipids in the control group over time that can, perhaps, be justified by the increased consumption of total fat, saturated fat, and cholesterol intake during the follow-up periods. Because in a study by Shahar, a positive significant relationship was found between saturated fat intake and serum lipids. There was, also, a positive significant association between cholesterol intake with LDL-C and total cholesterol levels (57). In other similar studies, fat intake was associated positively with increased serum cholesterol, LDL, and HDL $(30,57)$. Moreover, changes in serum lipids have been investigated in numerous studies in different seasons, and the findings of which are consistent with our findings. In this regard, in a study in Iran, LDL levels in winter were higher than its levels in summer (58). Other similar results were, also, found in studies by Ko (59) and Ockene (60). In spite of the significant increase in LDL levels and total cholesterol in control group, there was a significant reduction in experimental group that can, possibly, be the result of success of the treatment program of the current piece of research. Since dietary pattern is a crucial environmental factor in obesity, DASH diet as an appropriate dietary practice for adults (61) has shown beneficial effects in weight loss (54). In this study, the mean of participants' weight significantly decreased which is consistent with similar studies. For instance, in the study of Hinderliter, there was $7.8 \mathrm{~kg}$ weight loss after the intervention (62), and in the study of Barak (2013), there was a negative relationship between the adherence to DASH and obesity (63). This association was also seen in the study of Folsom in which adherence to DASH was inversely associated with mean of waist circumference and body mass index (64). Evidence shows that weight in obese hypertensive patients can be reduced by $3-9 \%$ with a healthy diet; besides weight reduction, it can also be effective in reducing systolic and diastolic BP (65). In another review, studying the efficacy of nutritional interventions on weight loss; after 2 to 4 years, weight loss was reported to be less than $5 \mathrm{~kg}$. Nutritional intervention can improve risk factors in cardiovascular disease (66). The importance of weight loss in these patients is to such an extent that obese hypertensive patients are more at the risk of atherosclerotic thrombotic disorders, increased LDL, decreased HDL, and left ventricular hypertrophy, than normotensive individuals (67). As far as the authors are concerned, despite the importance of weight loss in overweight patients, studies have shown that physicians had not paid enough attention to this issue and had not discussed with their patients the necessity of weight loss $(68,69)$. However, studies have shown that weight loss is a long-term strategy to maintain blood pressure in the normal range; therefore, weight loss should be recommended to patients with hypertension (70). One of the limitations in this research was conducted in a rural community therefore, findings cannot be generalized to urban areas, and therefore continued study conducted in rural cultures could be a possible course for future research.

\section{Conclusions}

To the knowledge of the researchers, this is the first study applying HPM in nutritional education for rural hypertensive patients. In this study, the effect of nutritional education and adherence to the recommended diets were, also, evaluated by laboratory indexes in addition to measuring dietary fat intake that offers the optimal approach for determining the effects of diet on blood pressure. The results of this study can be applicable to most hypertensive people in rural areas of Iran due to their similar socioeconomic status; therefore, the researchers suggest those involved in health care centers, evaluate this educational program in national health care services. As mentioned, nutritional education based on HPM, improved serum lipids and dietary fat intake among rural hypertensive patients. Hence, the results of this study support the efficacy of DASH developed for this study in managing BP and dietary behavior among urban hypertensive patients in Iran.

\section{Acknowledgments:}

This study was supported and funded by the Isfahan University of Medical Sciences (grant number 392132).

\section{Conflict of Interest:}

There is no conflict of interest to be declared.

Authors' contributions:

All authors contributed to this project and article equally. All authors read and approved the final manuscript. 


\section{References:}

1) Kokkinos P, Panagiotakos DB, Polychronopoulos E. Dietary influences on blood pressure: the effect of the Mediterranean diet on the prevalence of hypertension. J Clin Hypertens (Greenwich). 2005; 7(3): 165-70. PMID: 15785158.

2) Kamran A, Azadbakht L, Sharifirad Gh, Mahaki B, Sharghi A. Sodium Intake, Dietary Knowledge, and Illness Perceptions of Controlled and Uncontrolled Rural Hypertensive Patients. International Journal of Hypertension. 2014; 2014: 7. doi: 10.1155/2014/245480.

3) Chobanian AV, Bakris GL, Black HR, Cushman WC, Green LA, Izzo JL, et al. Seventh report of the Joint National Committee on Prevention, Detection, Evaluation, and Treatment of High Blood Pressure. Hypertension. 2003; 42(6): 1206-52. PMID: 14656957.

4) Appel LJ, Brands MW, Daniels SR, Karanja N, Elmer PJ, Sacks FM. Dietary approaches to prevent and treat hypertension: a scientific statement from the American Heart Association. Hypertension. 2006; 47(2): 296-308. PMID: 16434724.

5) Nazari R, Haji Ahmadi M, Dadashzade M, Asgari P. Study of hand hygiene behavior among nurses in Critical Care Units. IJCCN. 2011; 4(2): 93-6.

6) Karanja N, Erlinger Tp, Pao-Hwa L, Miller ER, Bray GA. The DASH diet for high blood pressure: from clinical trial to dinner table. Cleve Clin J Med. 2004; 71(9): 745-53. doi: 10.3949/ccjm.71.9.745. PMID: 15478706.

7) Mellen PB, Gao SK, Vitolins MZ, Goff DC Jr. Deteriorating dietary habits among adults with hypertension: DASH dietary accordance, NHANES 1988-1994 and 1999-2004. Arch Intern Med. 2008; 168(3): 308-14. PMID: 18268173.

8) Asghari G, Mirmiran P, Hosseni-Esfahani F, Nazeri P, Mehran M, Azizi F. Dietary quality among Tehranian adults in relation to lipid profile: findings from the Tehran Lipid and Glucose Study. J Health Popul Nutr. 2013; 31(1): 37-48. PMID: 23617203, PMCID: PMC3702357.

9) Salehi L, Haidari F. Efficacy of PRECEDE Model in Promoting Nutritional Behaviors in a Rural Society. irje. 2011; 6(4): 21-7.

10) Nemati A, Abbasgolizadeh N. Rahimi K. Nutritional Knowledge and Patterns of Women in Ardabil Province. Journal of Health and Hygeine. 2011; 2(3): 34-41.

11) Glanz K, Basil M, Maibach E, Goldberg J, Snyder D. Why Americans eat what they do: Taste, nutrition, cost, convenience, and weight control concerns as influences on food consumption. J Am Diet Assoc. 1998; 98(10): 1118-26. doi: 10.1016/S0002-8223(98)00260-0. PMID: 9787717.

12) Bertoni AG, Foy CG, Hunter JC, Quandt SA, Vitolins MZ, Whitt-Glover MC. A multilevel assessment of barriers to adoption of Dietary Approaches to Stop Hypertension (DASH) among African Americans of low socioeconomic status. J Health Care Poor Underserved. 2011; 22(4): 1205-20. doi: 10.1353/hpu.2011.0142. PMID: 22080704, PMCID: PMC3769217.

13) Erkoc SB, Isikli B, Metintas S, Kalyoncu C. Hypertension Knowledge-Level Scale (HK-LS): a study on development, validity and reliability. Int J Environ Res Public Health. 2012; 9(3): 1018-29. doi: 10.3390/ijerph9031018. PMID: 22690180, PMCID: PMC3367294.

14) Spencer A, Jablonski R, Loeb SJ. Hypertensive African American women and the DASH diet. Nurse Pract. 2012; 37(2): 41-6. doi: 10.1097/01.NPR.0000410278.75362.a2. PMID: 22252028.

15) Pawlak R, Colby S. Benefits, barriers, self-efficacy and knowledge regarding healthy foods; perception of African Americans living in eastern North Carolina. Nutr Res Pract. 2009; 3(1): 56-63. doi: 10.4162/nrp.2009.3.1.56. PMID: 20016703, PMCID: PMC2788162.

16) Moser RP, Green V, Weber D, Doyle C. Psychosocial Correlates of Fruit and Vegetable consumption among African American Men. J Nutr Educ Behav. 2005; 37(6): 306-14. PMID: 16242062.

17) Newell M, Modeste N, Marshak HH, Wilson C. Health beliefs and the prevention of hypertension in a black population living in London. Ethn Dis. 2009; 19(1): 35-41. PMID: 19341161.

18) Keshani P, Farvid MS. Perceived benefits and barriers regarding high fiber food intake in type 2 diabetes patients- A qualitative study. Iranian Journal of Nutrition Sciences \& Food Technology. 2012; 7(1): 11-22. Available from: http://nsft.sbmu.ac.ir/article-1-690-en.html.

19) Pires CG, Mussi FC. [Health beliefs regarding diet: a perspective of hypertensive black individuals]. Rev Esc Enferm USP. 2012; 46(3): 580-9. PMID: 22773477.

20) Burke LE, Wang J, Sevick MA. Self-monitoring in weight loss: a systematic review of the literature. J Am Diet Assoc. 2011; 111(1): 92-102. doi: 10.1016/j.jada.2010.10.008. PMID: 21185970, PMCID: PMC3268700. 
21) Wingo BC, Desmond RA, Brantley P, Appel L, Svetkey L, Stevens VJ, et al. Self-efficacy as a predictor of weight change and behavior change in the PREMIER trial. J Nutr Educ Behav. 2013; 45(4): 314-21. doi: 10.1016/j.jneb.2012.12.004. PMID: 23433966, PMCID: PMC4114041.

22) Parker WA, Steyn Np, Levitt NS, Lombard CJ. Health promotion services for patients having noncomminicable diseases: feedback from patients and health care providers in Cape Town, South Africa. BMC Public Health. 2012; (12): 503. doi: 10.1186/1471-2458-12-503.

23) Khatib R, Schwalm JD, Yusuf S, Haynes RB, McKee M, Khan M, et al. Patient and Healthcare Provider Barriers to Hypertension Awareness, Treatment and Follow Up: A Systematic Review and Meta-Analysis of Qualitative and Quantitative Studies. PLoS ONE. 2014; 9(1): e84238. doi: 10.1371/journal.pone.0084238. PMID: 24454721, PMCID: PMC3893097.

24) Kamran A, Sharifirad G, Azadbakht L. Assessing Nutritional Behaviors and Attitudes of rural Hypertensive Patients based on Pender Health Promotion Model. Ardabil University of medical Sciences. 2013.

25) Uchenna O, Ijeoma E, Pauline E, Sylvester O. Contributory Factors to Diabetes Dietary Regimen Non Adherence in Adults with Diabetes. World Academy of Science, Engineering and Technology. 2010; 45: 734.

26) Marcy TR, Britton ML, Harrison D. Identification of barriers to appropriate dietary behavior in low-income patients with type 2 diabetes mellitus. Diabetes Ther. 2011; 2(1): 9-19. doi: 10.1007/s13300-010-0012-6. PMID: 22127765, PMCID: PMC3124642.

27) Schlundt DG, Hargreaves MK, Buchowski MS. The eating behavior patterns questionnaire predicts dietary fat intake in African American women. J Am Diet Assoc. 2003; 103(3): 338-45. PMID: 12616256.

28) Jafari F, Kholdi N, Davati A, Nezamdust Z. The Study of Oils Consumption Pattern and Its Related Factors in east Tehran. JFUMS. 2013; 3(3): 202-7.

29) Azadbakht L, Fard NR, Karimi M, Baghaei MH, Surkan PJ, Rahimi M, et al. Effects of the Dietary Approaches to Stop Hypertension (DASH) eating plan on cardiovascular risks among type 2 diabetic patients: a randomized crossover clinical trial. Diabetes Care. 2011; 34(1): 55-7. doi: 10.2337/dc10-0676. PMID: 20843978, PMCID: PMC3005461.

30) Guo H, Xi J. [Effects of dietary lipids on serum lipid levels of hypertensive patients]. Zhonghua Yu Fang Yi Xue Za Zhi. 2002; 36(4): 250-3. PMID: 12411206.

31) Obarzanek E, Sacks FM, Vollmer WM, Bray GA, Miller ER 3rd, Lin PH, et al. Effects on blood lipids of a blood pressure-lowering diet: the Dietary Approaches to Stop Hypertension (DASH) Trial. Am J Clin Nutr. 2001; 74(1): 80-9. PMID: 11451721.

32) Whitt-Glover MC, Hunter JC, Foy CG, Quandt SA, Vitolins MZ, Leng I, et al. Translating the Dietary Approaches to Stop Hypertension (DASH) diet for use in underresourced, urban African American communities, 2010. Prev Chronic Dis. 2013; 10: 120088. doi: 10.5888/pcd10.120088. PMID: 23306077, PMCID: PMC3545703.

33) Rankins J, Sampson W, Brown B, Jenkins-Salley T. Dietary Approaches to Stop Hypertension (DASH) intervention reduces blood pressure among hypertensive African American patients in a neighborhood health care center. J Nutr Educ Behav. 2005; 37(5): 259-64. PMID: 16053815.

34) Appel LJ, Moore TJ, Obarzanek E, Vollmer WM, Svetkey LP, Sacks FM, et al. A clinical trial of the effects of dietary patterns on blood pressure. DASH Collaborative Research Group. DASH Collaborative Research Group. N Engl J Med. 1997; 336(16): 1117-24. doi: 10.1056/NEJM199704173361601. PMID: 9099655.

35) Sacks FM, Svetkey LP, Vollmer WM, Appel LJ, Bray GA, Harsha D, et al. Effects on blood pressure of reduced dietary sodium and the Dietary Approaches to Stop Hypertension (DASH) diet. DASH-Sodium Collaborative Research Group. N Engl J Med. 2001; 344(1): 3-10. PMID: 11136953.

36) Appel LJ, Champagne CM, Harsha DW, Cooper LS, Obarzanek E, Elmer PJ, et al. Effects of comprehensive lifestyle modification on blood pressure control: main results of the PREMIER clinical trial. JAMA. 2003; 289(16): 2083-93. PMID: 12709466.

37) Bray GA, Paeratakul S, Popkin BM. Dietary fat and obesity: a review of animal, clinical and epidemiological studies. Physiol Behav. 2004; 83(4): 549-55. PMID: 15621059.

38) Ferrara AL, Pacioni D, Fronzo V, Fronzo V, Russo BF, Staiano L, et al. Lifestyle educational program strongly increases compliance to nonpharmacologic intervention in hypertensive patients: a 2 -year followup study. J Clin Hypertens (Greenwich). 2012 14(11):767-72. PMID: 23126348 
39) Obarzanek E, Vollmer WM, Lin PH, Cooper LS, Young DR, Ard JD, et al. Effects of individual components of multiple behavior changes: the PREMIER trial. Am J Health Behav. 2007; 31(5): 545-60. PMID: 17555385.

40) Troyer JL, Racine EF, Ngugi GW, McAuley WJ. The effect of home-delivered Dietary Approach to Stop Hypertension (DASH) meals on the diets of older adults with cardiovascular disease. Am J Clin Nutr. 2010; 91(5): 1204-12. doi: 10.3945/ajcn.2009.28780. PMID: 20200258.

41) Racine E, Troyer JL, Warren-Findlow J, McAuley WJ. The effect of medical nutrition therapy on changes in dietary knowledge and dash diet adherence in older adults with cardiovascular disease. J Nutr Health Aging. 2011; 15(10): 868-76. PMID: 22159775.

42) Epstein DE, Sherwood A, Smith PJ, Craighead L, Caccia C, Lin PH, et al. Determinants and consequences of adherence to the dietary approaches to stop hypertension diet in African-American and white adults with high blood pressure: results from the ENCORE trial. J Acad Nutr Diet. 2012; 112(11): 1763-73. doi: 10.1016/j.jand.2012.07.007. PMID: 23000025, PMCID: PMC3483427.

43) Wilde DW, Massey KD, Walker GK, Vollmer A, Grekin RJ. High-fat diet elevates blood pressure and cerebrovascular muscle $\mathrm{Ca}(2+)$ current. Hypertension. 2000; 35(3): 832-7. PMID: 10720603.

44) Rasmussen BM, Vessby B, Uusitupa M, Berglund L, Pedersen E, Riccardi G, et al. Effects of dietary saturated, monounsaturated, and n-3 fatty acids on blood pressure in healthy subjects. Am J Clin Nutr. 2006; 83(2): 221-6. PMID: 16469978.

45) Watters JL, Satia JA. Psychosocial correlates of dietary fat intake in African-American adults: A crosssectional study. Nutr J. 2009; 8: 15. doi: 10.1186/1475-2891-8-15. PMID: 19320975, PMCID: PMC2667442.

46) Micha R, Mozaffarian D. Saturated fat and cardiometabolic risk factors, coronary heart disease, stroke, and diabetes: a fresh look at the evidence. Lipids. 2010; 45(10): 893-905. doi: 10.1007/s11745-010-3393-4. PMID: 20354806, PMCID: PMC2950931.

47) Lichtenstein AH, Appel LJ, Brands M, Carnethon M, Daniels S, Franch HA, et al. Diet and lifestyle recommendations revision 2006: a scientific statement from the American Heart Association Nutrition Committee. Circulation. 2006; 114(1): 82-96. doi: 10.1161/CIRCULATIONAHA.106.176158. PMID: 16785338 .

48) Ma Y, Olendzki B, Li W, Hafner A, Chiriboga D, Hebert J, et al. Seasonal variation in food intake, physical activity, and body weight in a predominantly overweight population. Eur J Clin Nutr. 2006; 60(4): 519-28. doi: 10.1038/sj.ejcn.1602346. PMID: 16340952, PMCID: PMC1428793.

49) Barnes TL, Crandell JL, Bell RA, Mayer-Davis EJ, Dabelea D, Liese AD. Change in DASH diet score and cardiovascular risk factors in youth with type 1 and type 2 diabetes mellitus: The SEARCH for Diabetes in Youth Study. Nutr Diabetes. 2013; 3: e91. doi: 10.1038/nutd.2013.32. PMID: 24126768, PMCID: PMC3817346.

50) Crawford P, Paden SL, Park MK. Clinical inquiries: What is the dietary treatment for low HDL cholesterol? J Fam Pract. 2006; 55(12): 1076-8. PMID: 17137545.

51) Asemi Z, Tabassi Z, Samimi M, Fahiminejad T, Esmaillzadeh A. Favourable effects of the Dietary Approaches to Stop Hypertension diet on glucose tolerance and lipid profiles in gestational diabetes: a randomised clinical trial. Br J Nutr. 2013; 109(11): 2024-30. doi: 10.1017/S0007114512004242. PMID: 23148885 .

52) Li ZK, Tang H, Gong RR, Lin J, Gan CF, Huang X, et al. No decrease of HDL cholesterol after 6 days of low fat and high carbohydrate diets in a young Chinese Han population. Sichuan Da Xue Xue Bao Yi Xue Ban. 2008; 39(4): 595-600. PMID: 18798502.

53) Veghari G, Sedaghat M, Joshghani H, Niknezad F, Angizeh A, Tazik E, et al. Plasma total cholesterol level and some related factors in northern Iranian people. J Nat Sci Biol Med. 2013; 4(2): 359-63. PMID: 24082732.

54) Blumenthal JA, Babyak MA, Hinderliter A, Watkins LL, Craighead L, Lin PH, et al. Effects of the DASH diet alone and in combination with exercise and weight loss on blood pressure and cardiovascular biomarkers in men and women with high blood pressure: the ENCORE study. Arch Intern Med. 2010; 170(2): 126-35. PMID: 20101007, PMCID: PMC3633078.

55) Roussell MA, Hill AM, Gaugler TL, West SG, Heuvel JP, Alaupovic P, et al. Beef in an Optimal Lean Diet study: effects on lipids, lipoproteins, and apolipoproteins. Am J Clin Nutr. 2012; 95(1): 9-16. PMID: 22170364 , PMCID: PMC3238465.

56) Nowson CA, Worsley A, Margerison C, Jorna MK, Frame AG, Torres SJ, et al. Blood pressure response to dietary modifications in free-living individuals. J Nutr. 2004; 134(9): 2322-9. PMID: 15333723. 
57) Shahar DR, Froom P, Harari G, Yerushalmi N, Lubin F, Kristal-Boneh E. Changes in dietary intake account for seasonal changes in cardiovascular disease risk factors. Eur J Clin Nutr. 1999; 53(5): 395-400. PMID: 10369496.

58) Hadaegh F, Harati H, Zabetian A, Azizi F. Seasonal variability of serum lipids in adults: Tehran Lipid and Glucose Study. Med J Malaysia. 2006; 61(3): 332-8. PMID: 17240585.

59) Ko YS, Ahn HS. Seasonal Difference of Nutrient Intake, Serum Lipid and Antioxidative Index in Female College Students. Korean J Community Nutr. 2007; 12(2): 142-9.

60) Ockene IS, Chiriboga DE, Stanek EJ 3rd, Harmatz MG, Nicolosi R, Saperia G, et al. Seasonal variation in serum cholesterol levels: treatment implications and possible mechanisms. Arch Intern Med. 2004; 164(8): 863-70. doi: 10.1001/archinte.164.8.863. PMID: 15111372.

61) Dietary Guidelines Advisory Committee Report of the Dietary Guidelines Advisory Committee on the dietary guidelines for Americans. Ed Washington DC: US Government Printing Office. United States Department of Agriculture. 2010.

62) Hinderliter AL, Sherwood A, Craighead LW, Lin PH, Watkins L, Babyak MA, et al. The Long-Term Effects of Lifestyle Change on Blood Pressure: One-Year Follow-Up of the ENCORE Study. Am J Hypertens. 2014; 27(5): 734-41. doi: 10.1093/ajh/hpt183. PMID: 24084586, PMCID: PMC3978946.

63) Barak F, Falahi E, Keshteli AH, Yazdannik A, Esmaillzadeh A. Association between adherence to the DASH diet and obesity among Isfahani female-nurses. Public Health Nutr. 2015; 18(4): 705-12. doi: 10.1017/S1368980014000822. PMID: 24810207.

64) Folsom AR, Parker ED, Harnack LJ. Degree of concordance with DASH diet guidelines and incidence of hypertension and fatal cardiovascular disease. Am J Hypertens. 2007; 20(3): 225-32. doi: 10.1016/j.amjhyper.2006.09.003. PMID: 17324731, PMCID: PMC2020811.

65) Siebenhofer A, Jeitler K, Horvath K, Berghold A, Siering U, Semlitsch T. Long-term effects of weightreducing diets in hypertensive patients. Cochrane Database Syst Rev. 2013; (3): CD007654. doi: 10.1002/14651858.CD007654.pub3. PMID: 23543553.

66) Douketis JD, Macie C, Thabane L, Williamson DF. Systematic review of long-term weight loss studies in obese adults: clinical significance and applicability to clinical practice. Int J Obes (Lond). 2005; 29(10): 1153-67. doi: 10.1038/sj.ijo.0802982. PMID: 15997250.

67) Mohan V, Deepa M, Farooq S, Datta M, Deepa R. Prevalence, awareness and control of hypertension in Chennai--The Chennai Urban Rural Epidemiology Study (CURES-52). J Assoc Physicians India. 2007; 55: 326-32. PMID: 17844691.

68) Bray G, Look M, Ryan D, Bray G, Look M, Ryan D. Treatment of the obese patient in primary care: targeting and meeting goals and expectations. Postgrad Med. 2013; 125(5): 67-77. doi: 10.3810/pgm.2013.09.2692. PMID: 24113665

69) Oardley D, Sherman C, Ambrosetti L, Lewis J. Obesity evaluation and intervention during family medicine well visits. J Am Board Fam Med. 2007; 20(3): 252-7. doi: 10.3122/jabfm.2007.03.060127. PMID: 17478657.

70) Davis BR, Blaufox MD, Oberman A, Wassertheil-Smoller S, Zimbaldi N, Cutler JA, et al. Reduction in long-term antihypertensive medication requirements. Effects of weight reduction by dietary intervention in overweight persons with mild hypertension. Arch Intern Med. 1993; 153(15): 1773-82. PMID: 8333814. 